April - 2018

\title{
Online Course Enrollment in Community College and Degree Completion: The Tipping Point
}

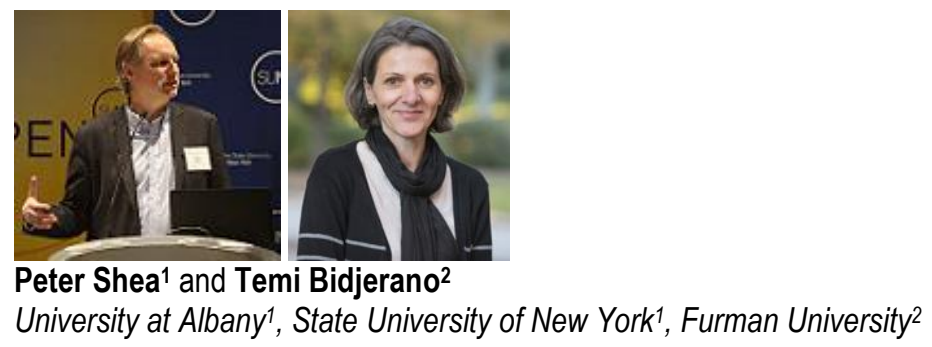

\begin{abstract}
Recent research indicates that certain students are at risk of lower levels of academic performance in online settings when compared to peers who study only in the classroom. Community college students have been a population of particular concern. In this paper, we hypothesize that online course load and institutional quality may impact outcomes for such students at risk for lower levels of degree attainment. Using comprehensive data from the 30 community colleges $(n=45,557)$ of the State University of New York (SUNY), we conducted a state-wide study to examine whether there is a "tipping point" at which online course load becomes problematic for community college learners seeking to attain a degree through a mix of online and face-to-face coursework. We also test the conjecture that some institutions may excel at supporting online learner success among more at risk populations who choose online study. Results indicate that community college students who take more than $40 \%$ of their courses online begin to lose the benefits of enhanced degree completion conferred through a mix of online and face-to-face enrollment. Moderating variables are also identified and discussed.
\end{abstract}

Keywords: online learning, community colleges, retention, degree completion 


\section{Introduction}

Educational attainment is a significant predictor of a host of individual and societal benefits. Individuals with higher levels of education earn more, pay more taxes, and are more likely than others to be employed. As one recent report describes the relationship, "College education increases the chance that adults will move up the socioeconomic ladder and reduces the chance that adults will rely on public assistance" (Ma, Pender, \& Welch, 2016, p.4). Online education has increased access to these benefits for many millions of adult citizens (Allen \& Siemen, 2016). The flexibility and convenience of online learning can open doors to a better life for those who avail themselves of the opportunity. Community colleges have been particularly effective in offering online education with a higher proportion of these institutions enrolling online student than four year colleges (McFarland et al., 2017).

Copious research suggests that online and classroom-based instruction result in equivalent outcomes for student in most higher education settings. Reporting on 16 meta-analyses, Bernard Borokhovski, Schmid, Tamim, and Abrami, 2014) (2014) concluded that thousands of studies indicate that online learners and classroom learners succeed at equivalent rates at a wide variety of outcome measures. There is significant variability across studies, however, with many finding that online students succeed at higher rates, and just as many finding that classroom students succeed at higher rates. For decades researchers have been encouraged to investigate "what makes the difference?" in this no-significant difference literature (Zhao, Lei, Yan, Lai, \& Tan, 2005). This study undertakes that goal with a sub-population already determined to be at risk for lower academic outcomes: community college students.

Our questions for this study grow out of an emerging line of inquiry that consistently identifies lower performance among community college students who take online courses compared to their classroomonly counterparts. The possibility of impaired academic performance among certain students is important as the likelihood of attaining an educational credential, and its individual and societal benefits, is jeopardized. This is especially concerning among the population studied here as community college serves as a leveler, and in many cases, provides access to higher education regardless of prior academic preparation.

\section{Review of Related Research}

A series of rigorous state-wide studies by Jaggars and Xu (2010) and Xu and Jaggars (2011; 2013) found that community college students in Virginia and Washington State had lower performance (higher course dropout rates and lower grades) in online courses in comparison to face-to-face courses and that these negative findings were amplified with certain sub-groups (male students, younger students, Black students, and students with lower GPAs).

Parts of this line of research are replicated and extended by Johnson, Cuellar Mejia, \& Cook (2015) among the community college students in California who also found lower course grades, higher course withdrawal, and an amplification of achievement gaps between majority and minority students. More recent research in a large private-for-profit institution supports some of these findings (Bettinger, Fox, Lob, \& Taylor, 2017) relating to exacerbated online achievement gaps. 
Beyond course level outcomes, program level outcomes for online college students were also problematic in some large-scale studies. Students in both the Virginia and Washington State community college systems who took one or more online courses in their first semester were 4 to $5 \%$ less likely to return for the following semester (Jaggars \& Xu, 2010). Students who took a higher ratio of credits online were also less likely to earn a degree or transfer to a four-year institution than students who took a lower proportion of online credits (Xu \& Jaggars, 2011).

However, conflicting findings in this area of investigation exist. For example, Wladis, Conway, \& Hachey (2016) found that while students enrolled in online courses were more likely to drop out of college, online course outcomes had no direct effect on college persistence. Other researchers, using a large, multi-state, federated data set of more than 600,000 students participating in the Predictive Analytics Reporting Framework (PAR) found that taking some online courses did not result in lower retention rates for students enrolled in primarily face-to-face community colleges (James, Swan, \& Daston, 2016). The authors found no differences in retention between delivery mode for students enrolled in primarily face-to-face, four-year universities, while at primarily online institutions, students taking some online and some classroom courses had slightly better odds of being retained than students taking exclusively face-to-face or exclusively online courses. Consistent with studies in Virginia, Washington, and California online course load was a predictor of lower academic outcomes. Community college students who take a higher load of online courses are also less likely to complete their courses successfully with a grade of $\mathrm{C}$ or higher.

Additional research indicates that the program-level students who take online courses attain degrees at higher rates than classroom-only students, despite lower course-level performance. In studies at both the state level (Johnson, Cuellar Majia, \& Cook, 2015) and national level (Shea \& Bidjerano, 2014) authors found that students who took at least some online courses were more likely to earn an associate's degree or transfer to a four-year institution than those who did not. Further, Shea and Bidjerano (2017), investigating the 30 community colleges of the State University of New York, did not replicate the finding that online study amplifies achievement gaps between minority and majority students. While students in online courses had slightly lower grades in four of seven semesters compared to classroom courses they had taken, achievement gaps were equivalent to what they were in classroom settings. At the national level, students with some online coursework were not more likely to dropout compared to classroom-only peers (Shea \& Bidjerano, 2016).

While disagreement exists regarding specific findings, taken together these large-scale studies firmly identify community college students to be at potential significant risk of worse outcomes online than in face-to-face settings. One consistent finding is that online course load appears to have a negative impact on academic performance. For example, in both Virginia and Washington State, students who took a higher proportion of credits online were less likely to obtain a degree or transfer to a four-year institution than students who took lower proportions of online credits (Jaggars, Edgecombe, \& Stacey, 2013). Furthermore, among the many institutional studies in the PAR framework (James et al., 2016), odds ratio analysis indicated that students mixing online and face-to-face courses, or taking only face-to-face courses, had up to 1.6 times greater odds of being retained than fully online students. Shea and Bidjerano (2017) found similar results among students in New York State. The odds of degree attainment were about 1.5 times higher for SUNY students with a combination of online and traditional courses compared to students with 
classroom courses only. However, the odds of degree attainment were about 2 to 3 times lower for fully online students relative to students with a mix of online and classroom courses. There appears to be a point at which the taking of online courses results in diminishing returns regarding the attainment of a college degree.

We know that taking some courses online assists students toward the beneficial goal of degree attainment, however, taking all online courses results in lower levels of retention across studies in which this outcome is assessed. This study seeks to investigate the "tipping point" at which the proportion of online course enrollment leads to impaired degree completion. Specifically this paper investigates the research questions below.

\section{Research Questions}

RQ1: Given recent evidence suggesting that online coursework may limit a community college student's chances for success, is there a threshold for online course enrollment intensity that jeopardizes one's prospects for successful completion of a college degree?

RQ2: Does the intensity of online coursework modify the effect of traditional predictors of degree completion such as enrollment status, qualification for remedial education, grades, course passing rates, etc.?

RQ3: Does an institution's demonstrated overall capacity to graduate students as compared to peer institutions impact graduation rates of students who take online classes?

\section{Method}

This study uses secondary data analysis to identify predictors of variance in degree attainment among community college students who registered in online coursework at varying levels. The goal of this method is to understand the impact of online course taking patterns on the completion of college credentials net of other known correlates of degree completion applying both single and multilevel regression analysis with a large sample.

\section{Data Sources}

The analytic sample consists of community college students who first enrolled in an Associate degree program in a two-year SUNY institution in Fall $2012(n=45,557)$. Distribution of major demographic characteristics is given in Table 1. The sample is predominantly Caucasians but evenly split in terms of gender. The mean age of the sample at time of first enrollment was 20 years of age $(S D=5.26$, Range $=16.08$ - 80.17). Race/ethnicity information was missing for about 1,500 (3.36\%) sample members. In order to include these cases in subsequent analyses, I used single model-based imputation as executed in Mplus. 
Table 1

Sample Demographics $(n=45,557)$

\begin{tabular}{llrr}
\hline Characteristic & & \multicolumn{2}{c}{ Pct. } \\
\hline Gender & Male & 22,987 & 50.46 \\
& Female & 22,570 & 49.54 \\
Race/ Ethnicity & Caucasian & 29,281 & 64.27 \\
& African American & 6,832 & 15.00 \\
& Asian & 1,170 & 2.57 \\
& Hispanic & 6,502 & 14.27 \\
\multirow{6}{*}{ Residency status } & Other & 1,772 & 3.89 \\
& In-state & 44,583 & 97.86 \\
& Out-of-state & 595 & 1.31 \\
& International & 379 & .83 \\
Military affiliation & & 698 & 1.53 \\
\hline
\end{tabular}

The research questions were addressed by means of a series of single-level and multilevel logistic analyses. The outcome was defined as attainment of a degree of any kind (certificate, associate, or bachelor) for the first time within our 13 semester time frame from Fall 2012 to Fall 2015. The main factor of interest was online load, defined as the proportion of online credits attempted of the total credits attempted by a student. All models included controls for traditional predictors of degree attainment consisting of demographic factors (gender, age, caucasian vs. minority), first semester indicators (whether the student was a Pell grant recipient, qualified for remedial coursework, and first community college institution when he/she began an associate's degree program for the first time), last semester indicators (number of credits completed relative to total number of credits attempted in one's last semester, last semester GPA, last program (humanities vs. other), last institution's graduation rates, and sector of last institution (CC vs. other), and cumulative measures (whether the student ever transferred to a four-year institution, total number of semesters being enrolled part or full-time). Controls were chosen on theoretical and empirical grounds.

\section{Results}

In our first model, we examined the effect of first campus of enrollment in a single-level regression to roughly estimate the degree of variability in degree attainment attributable to the student's first campus. The institution of first enrollment was modeled as a predictor with 30 dummy variables, one for each campus and one omitted as a reference category. Results show that first campus has a significant effect on degree attainment: the extent to which a student has a chance to attain a degree partly depends on the specific community college campus attended while enrolled for the first time. Traditional indicators of success such as gender, age, minority status, grades, successful course completion, and number of semesters of full or part-time enrollment (see Table 2 for all significant effects) were found to be viable 
predictors for the odds of degree completion. Controlling for all variables of the model, a higher online course load significantly decreases one's chances for completing a college degree.

Since campus and program variation in degree completion was substantial, remaining logistic regression analyses were carried out as cross-classified models with random intercepts. In these models, student first campus of enrollment $(n=30)$ was crossed with student last campus of enrollment $(n=57)$ while the student last known program of study $(n=2,400)$ was nested within student last campus of enrollment. The intercepts of first campus, last campus, and last known program were allowed to vary.

The baseline cross-classified model (Model 2) preserved the direction of the effects from the single-level analyses but produced slight changes in the magnitude of these effects.

Table 2

Results from Multilevel Logistic Analysis ( $n=45,557)$

\begin{tabular}{|c|c|c|c|c|c|c|c|c|}
\hline & Model 1 & & Model 2 & & Model 3 & & Model 4 & \\
\hline Fixed effects & Est. & SE & Est. & SE & Est. & $\mathrm{SE}$ & Est. & $\mathrm{SE}$ \\
\hline Intercept & $-5.476^{* * * *}$ & .154 & $-6.347^{* * *}$ & .195 & $-6.421^{* * *}$ & .195 & $-6.352^{* * * *}$ & .196 \\
\hline $\mathrm{Tr} \_4 \mathrm{yr}$ & .116 & .121 & .135 & .160 & .134 & .161 & .144 & .161 \\
\hline Female & $.139^{* * *}$ & .029 & $.169^{* * * *}$ & .032 & $.158^{* * * *}$ & .033 & $.155^{* * *}$ & .033 \\
\hline Age & $-.035^{* * *}$ & .003 & $-.035^{* * *}$ & .003 & $-.033^{* * *}$ & .003 & $-.033^{* * *}$ & .003 \\
\hline Caucasian & $.277^{* * *}$ & .034 & $.280^{* * * *}$ & .036 & $.272^{* * *}$ & .037 & $.271^{* * *}$ & .037 \\
\hline Pell & .052 & .030 & .055 & .032 & .059 & .033 & .060 & .033 \\
\hline Remedial & $-.517^{* * * *}$ & .031 & $-.562^{* * *}$ & .033 & $-.567^{* * * *}$ & .034 & $-.601^{* * *}$ & .038 \\
\hline L_Passed & $2.578^{* * *}$ & .074 & $2.685^{* * * *}$ & .078 & $2.702^{* * *}$ & .079 & $2.704^{* * *}$ & .079 \\
\hline L_Pr_Hum & $-.269^{* * * *}$ & .031 & $-.145^{* *}$ & .056 & $-.135^{* *}$ & .057 & $-.131^{* * * *}$ & .057 \\
\hline L_GPA & $.518^{* * *}$ & .018 & $.553^{* * * *}$ & .019 & $.55^{* * * *}$ & .020 & $.55^{* * * *}$ & .020 \\
\hline Sem & $.300^{* * * *}$ & .008 & $.337^{* * *}$ & .009 & $.328^{* * *}$ & .009 & $.327^{* * * *}$ & .009 \\
\hline L_InstGR & $-.005^{* * *}$ & .002 & $-.007^{*}$ & .004 & -.007 & .004 & -.008 & .004 \\
\hline L_InstSec & $.385^{* * *}$ & .119 & $1.169^{* * *}$ & .196 & $1.186^{* * *}$ & .197 & $1.159^{* * * *}$ & .197 \\
\hline ONL & $-.235^{*}$ & .111 & -.188 & .123 & $1.597^{* * *}$ & .268 & .046 & .445 \\
\hline Camp_F & Omitted $^{a}$ & & & & & & & \\
\hline Onl x Onl & & & & & $-2.778^{* * *}$ & .195 & $-2.577^{* * * *}$ & .012 \\
\hline Onl x LInstGR & & & & & & & $.047^{* * *}$ & .254 \\
\hline Onl x Remedial & & & & & & & $.553^{*}$ & .196 \\
\hline Wald Chi (df) & \multicolumn{2}{|l|}{$7388.64(41)$} & \multicolumn{2}{|l|}{ 7124.47(13) } & \multicolumn{2}{|c|}{$5364.60(14)$} & \multicolumn{2}{|c|}{$5377.19(16)$} \\
\hline$L L$ & \multicolumn{2}{|l|}{$-15,277.13$} & \multicolumn{2}{|l|}{$-15,332.60$} & \multicolumn{2}{|l|}{$-14,941.00$} & \multicolumn{2}{|l|}{$-14,902.75$} \\
\hline & mis & $n c$ & Iorror & & & & & \\
\hline Campus_F & - & - & .169 & .061 & .170 & .062 & .159 & .059 \\
\hline
\end{tabular}




\begin{tabular}{lllllllll} 
Campus_L & - & - & .581 & .091 & .584 & .091 & .580 & .091 \\
Last_Program & - & - & .583 & .062 & .585 & .062 & .584 & .062 \\
\hline
\end{tabular}

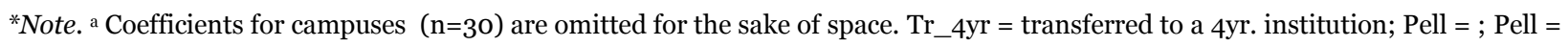
Pell grant recipient in Fall 2012; Remedial = qualified for remedial coursework in Fall 2012; L_Passed = percent of courses with passing grade in last semester; L_Pr_Hum = last known program is in the Humanities; L_GPA = last semester Grade Point Average; Sem = number of semesters enrolled; L_InstGR = graduation rates of last institution; L_InstSec = sector of last institution; ONL = online load; Camp_F = campus enrolled for the first time in Fall 2012.

To address RQ1, we added a polynomial effect (quadratic term) of online load. The addition resulted in an improved model fit, LR $(d f=1)=57.05, p<.001$, indicating that steady increases in online coursework intensity improved a student chances for degree completion up to a certain point after which a sharp decline in the odds for degree completion occur (See Figure 1). More precisely, the threshold for beneficial online load is about $40 \%$ of all courses.

In reference to RQ2, we explored 2-way and 3-way interactions between online load and the remaining control factors. Interactions were tested one at a time. Initial estimates indicated that the effect of online course load depends on the graduation rate for the last institution attended (a proxy measure of institutional effectiveness), successful completion of courses in one's last semester, total number of semesters of full or part-time enrollment, and whether the student qualified for remedial coursework. When all significant interactions were considered simultaneously in the single model with the polynomial term for load, only two of the four retained significance (see Model 4). The model with all significant interactions included was significantly better with just a polynomial term for online load, $\operatorname{LR}(d f=3)=76.52, p<.00)$.

The interaction between the quality of the last institution attended and the online course load (depicted in Figure 1) is noteworthy. Figure 2 shows the predicted probability of degree completion as a function of an institution's overall average graduation rates (with categories of low, medium, and high) and proportion of online course load. In institutions with relatively low overall graduation rates, a student's chance for degree completion is low irrespective of the overall number of online credits attempted. At the same time, probability of degree attainment is associated with increases in online load growing exponentially for students enrolled in more effective institutions.

Lastly, as shown in Figure 3, the interaction between remedial status in a student's first semester and the online load was marginally significant; nevertheless, it suggests significant differences in graduation rates between students who qualify for remedial education and those who do not in the lower range of online course load. 


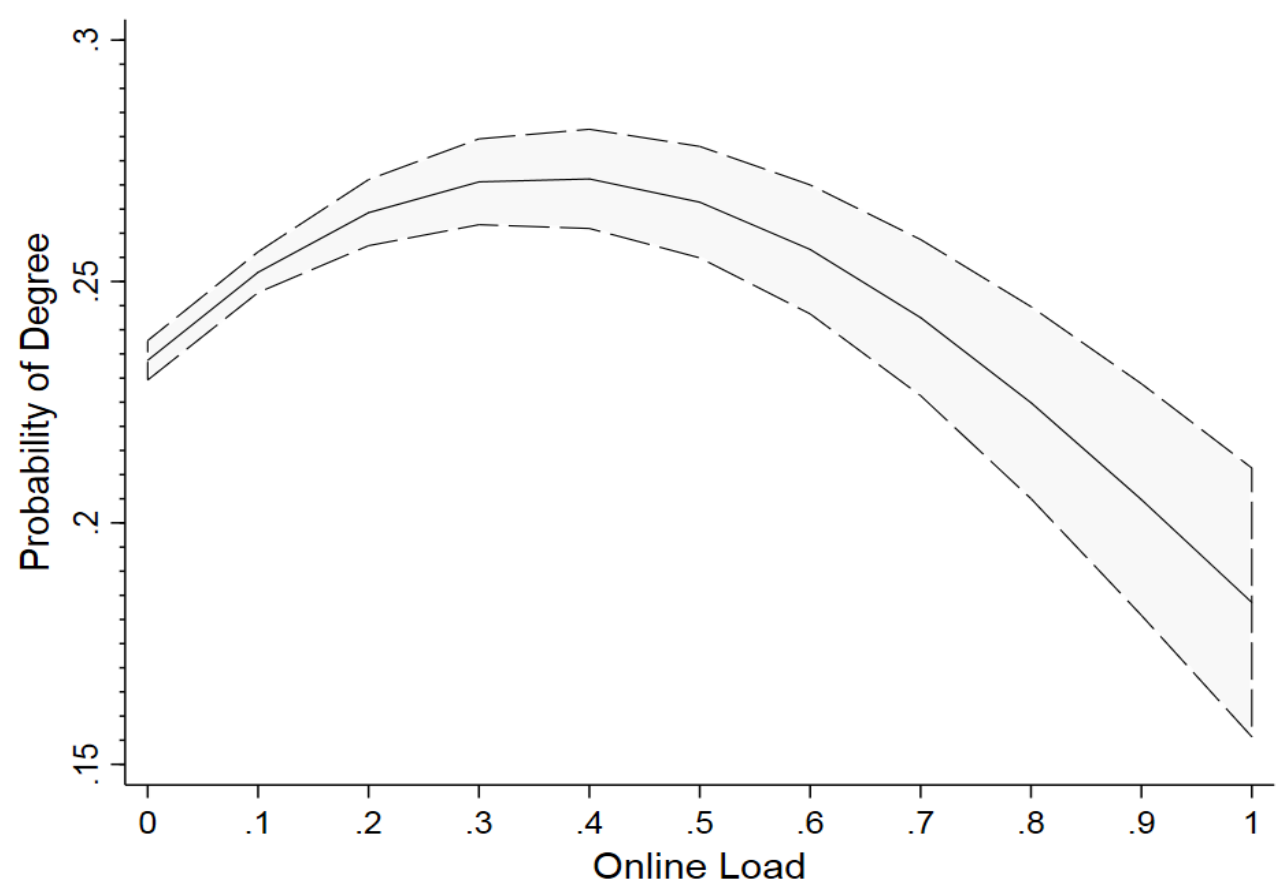

Figure 1. Effect of online course load on degree completion.

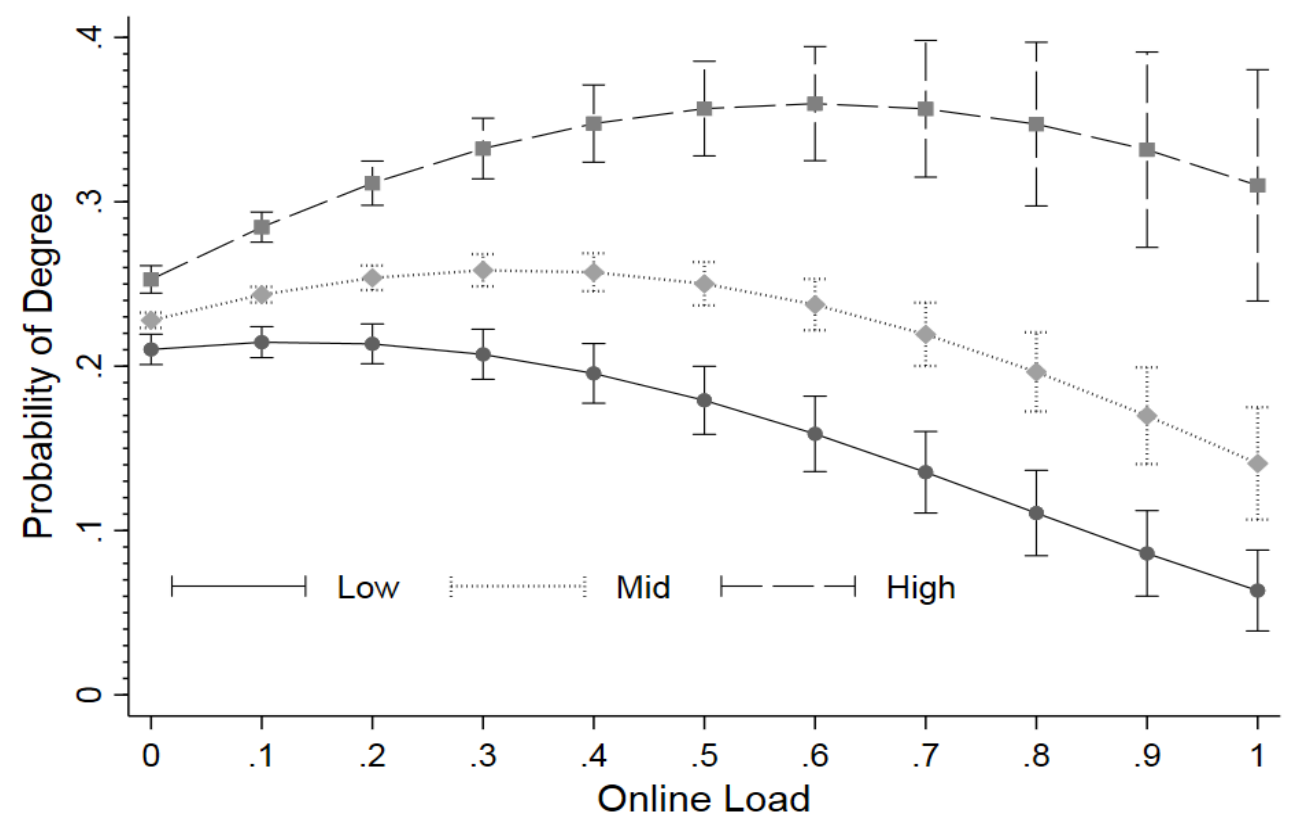

Figure 2. Interaction between online load and overall institutional graduation rates. 


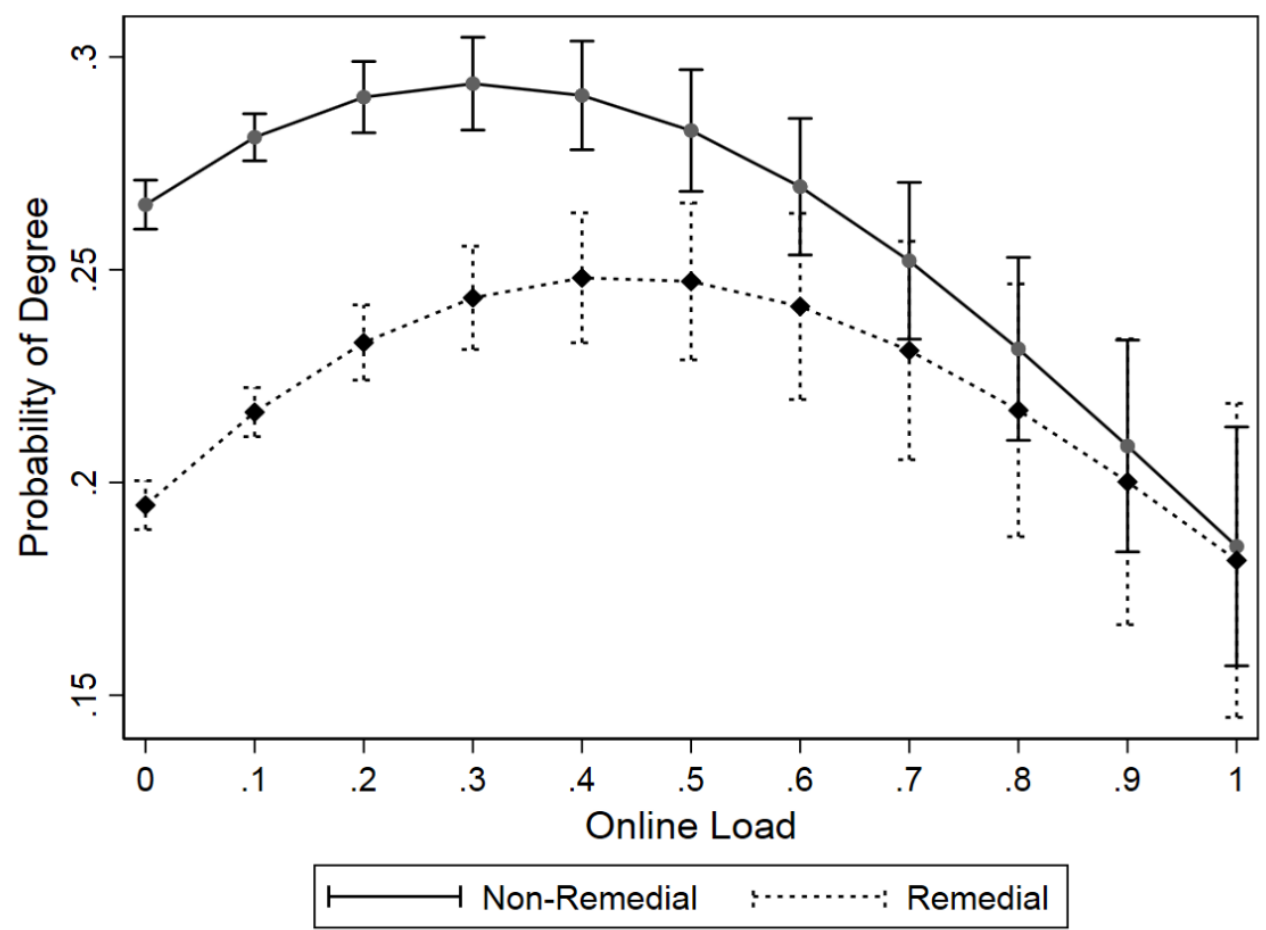

Figure 3. Interaction between remedial status in fall 2012 and online load.

\section{Discussion}

In this paper, we discussed the opportunity that online education represents in attainment of valuable college credentials. We presented a brief review of large-scale and rigorous research suggesting that community college students may struggle in online settings. We reviewed evidence that higher online course loads and exclusive online college enrollment (as opposed to a mix of online and classroom study) are predictive of reduced degree completion, while, paradoxically, a mix of online and classroom enrollment predicts higher degree completion. We sought to understand the "tipping point" for the beneficial effect of online enrollment on degree completion and whether overall institutional degree completion rates moderate the relationship between online course load and graduation. Results indicate that a load of approximately $40 \%$ of coursework is the upper limit for the beneficial effect of online enrollment on degree completion. Beyond that level, students attain college credentials at lower levels than their classroom-only counterparts. Overall, these results suggest that most community college students should be advised to enroll in face-to-face courses primarily and supplement these courses with online courses at a ratio of three face-to-face courses to two online courses for full-time students.

However, the overall graduation rate of the specific institution moderates this effect with less effective institutions representing particularly poor choices for online study as a path to college degree attainment. 
Conversely, institutions with higher overall graduation rates have higher tipping points for mixing online and classroom study as a pathway to degree completion. Students who enrolled at more effective institutions with the highest graduation rates can mix up to $60 \%$ of online coursework with classroom study as opposed to the average of $40 \%$ at all institutions and only $10 \%$ at the least effective institutions.

Again, at a practical level, students enrolled in institutions that are generally more effective in graduating students may be advised to take a higher ratio of online to classroom courses - approximately three online courses and two classroom courses for full-time students. Students studying in institutions with lower graduation rates should be advised to enroll almost exclusively in classroom coursework, with perhaps one online course per term for full-time students.

Finally, while overall, students who qualify for remedial education tend to have worse graduation rates, they improve their chances for graduation through a mix of online and classroom instruction equivalent to students who do not qualify for remedial education. Non-remedial students have significantly higher rates of graduation than do remedial students until they hit a threshold of $50 \%$ online courses after which their chances of graduation equalize with remedial students as indicated by overlapping confidence intervals. These interactions are important for both remedial and non-remedial populations enrolled in online courses. Students who qualify for remedial education need not be advised away from taking online courses necessarily. Although graduating at lower rates in general, the benefits of mixing face-to-face and online coursework on degree attainment is equivalent for both remedial and non-remedial students. In general, remedial students can be advised to mix online and classroom courses on par with non-remedial students - approximately three face-to-face courses and two online courses appears to be the mix that confers benefits regarding enhanced degree attainment. All such recommendations need to be interpreted in light of the specific needs of individual students who may not always have an option for on-campus study.

Future researchers should examine the interactions between institutional ability to graduate students generally and remedial student online benefits. It is likely the case that remedial students at colleges with lower graduation rates in general may experience reduced benefits of online study in relation to degree completion. There are numerous other variables that may also mediate the online learning benefit, including the quality of course design, student support infrastructure, faculty development, and subsequent diligence of instructors in monitoring student progress. Future research should examine interactions among these variables and the mix of online course load on degree attainment. 


\section{References}

Allen, I. E., \& Seaman. J. (2016). Online report card: Tracking online education in the United States. Babson Survey Research Group and Quahog Research Group, LLC. Retrieved from http://onlinelearningsurvey.com/reports/onlinereportcard.pdf

Bernard, R., Borokhovski, E, Schmid, R., Tamim, R., \& Abrami, P. (2014). A meta-analysis of blended learning and technology use in higher education: From the general to the applied. Journal of Computing in Higher Education, 26(1), 87-122. doi: 10.1007/s12528-013-9077-3

Bettinger, E., Fox, L., Loeb, S., \& Taylor, E. (2017). Changing distributions: How online college classes alter student and professor performance. American Economic Review, 107(9), 2855-2875.

Jaggars, S. S., Edgecombe, N., \& Stacey, G. W. (2013). What we know about online course outcomes: Research overview. New York: Columbia University, Community College Research Center. Retrieved from http://ccrc.tc.columbia.edu/media/k2/attachments/What-We-Know-AboutOnline-Course-Outcomes.pdf

Jaggars, S. S., \& Xu, D. (2010). Online learning in the Virginia Community College system. New York, NY: Columbia University, Teachers College, Community College Research Center.

James, S., Swan, K., \& Daston, C. (2015). Retention, progression and the taking of online courses. Online Learning, 2o(2). doi:http://dx.doi.org/10.24059/olj.v20i2.780

Johnson, H., Cuellar Mejia, M., \& Cook, K. (2015). Successful online courses in California's community colleges. San Francisco, CA: Public Policy Institute of California.

Ma, J., Pender, M., \& Welch, M. (2016). Education pays 2016: The benefits of higher education for individuals and society. New York: College Board.

McFarland, J., Hussar, B., de Brey, C., Snyder, T., Wang, X., Wilkinson-Flicker, S., ... Hinz, S. (2017). The condition of education 2017 (NCES 2017-144). U.S. Department of Education. Washington, DC: National Center for Education Statistics. Retrieved from https://nces.ed.gov/pubsearch/pubsinfo.asp?pubid=2017144

Shea, P., \& Bidjerano, T. (2014). Does online learning impede degree completion? A national study of community college students. Computers \& Education, 75, 103-111.

Shea, P., \& Bidjerano, T. (2016). A national study of differences between distance and non-distance community college students in time to first associate degree attainment, transfer, and dropout. Online Learning, 2O(3), 7-19.

Shea, P., \& Bidjerano, T. (2017). Online learning in the 30 community colleges of the State University of New York: Differences in outcomes between classroom and online coursework. In J. Johnston (Ed.), Proceedings of EdMedia: World conference on educational media and technology 2017 
(pp. 1192-1198). Waynesville, NC: Association for the Advancement of Computing in Education (AACE).

Wladis, C., Conway, K., \& Hachey, A. (2016). Assessing readiness for online education - Research models for identifying students at risk. Online Learning, $20(3)$.

doi:http://dx.doi.org/10.24059/olj.v20i3.980

Xu, D., \& Jaggars, S. S. (2011). Online and hybrid course enrollment and performance in Washington State community and technical colleges (CCRC Working Paper No. 31). New York, NY: Columbia University, Teachers College, Community College Research Center.

Xu, D., \& Jaggars, S. S. (2013). Adaptability to online learning: Differences across types of students and academic subject areas (CCRC Working Paper No. 54). New York, NY: Columbia University, Teachers College, Community College Research Center.

Zhao, Y., J. Lei, B. Yan, C. Lai, \& H. S. Tan. (2005). What makes the difference? A practical analysis of research on the effectiveness of distance education. Teachers College Record, 107(8), p18361884 .

\section{Athabasca}

University

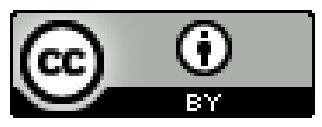

